\title{
The Roles of Fermentation Technologies in Mulberry Foods Processing: Application and Outlooks
}

\author{
Yu-Xiao Zou ${ }^{1-3 *}$, Wei-Zhi Shen ${ }^{1-3}$, Si-Yuan Wang ${ }^{1-3}$, Sen-Tai Liao ${ }^{1-3}$ and Fan Liu' \\ ${ }^{1}$ Sericultural \& Agri-Food Research Institute, Guangdong Academy of Agricultural Sciences, Guangzhou, P.R. China \\ ${ }^{2}$ Key Laboratory of Functional Foods, Ministry of Agriculture, Guangzhou, P.R. China \\ ${ }^{3}$ Guangdong Key Laboratory of Agricultural Products Processing, Guangzhou, P.R. China
}

\begin{abstract}
The application of microbial transformation technique makes it possible to provide commercial mulberry foods with stable quality as well as keeping its original nutrition. Food-grade yeasts, lactic acid bacteria and acetic acid bacteria have been used in mulberry foods fermentation in recent years. With considerable research work on medicinal and nutritious value of mulberry around the world, mulberry has been commercially processed into red wine, yoghurt and vinegar which are welcomed by more and more consumers all over the world.
\end{abstract}

Keywords: Mulberry foods; Fermentation technologies; Application; Outlooks

\section{Introduction}

Mulberry trees grow in a wide range of climatic, topographical and soil conditions and are widely distributed, from temperate to subtropical regions of the Northern hemisphere to the tropics of the Southern hemisphere [1]. The reasons for planting mulberry trees differ between Asian and European countries. In China and India, the mulberry foliages were used to feed silkworms and make money from cocoons, while partial mulberries is used as herbal medicine two decades ago. However, in many European countries, particularly Turkey and Greece, mulberries were grown for fruits rather than for their foliages [2]. Recently, with the improvement in science, the popularityof mulberry has become more and more positive because of its nutritional and therapeutic characteristics and attractive taste [3]. Mulberry foods development is causing extensive concern both in west and east. Nevertheless, its soft flesh makes it susceptible to treatment and transportation as a fresh fruit, as well as the difficultiesin harvesting large amounts of this fruit due to the location of the trees. In this case, its commercialization on a large scale as a fresh fruit is unviable. However, the application of microbial transformation technique makes it possible to provide commercial mulberry foods with stable quality as well as keeping its original nutrition. Food-grade yeasts, lactic acid bacteria and acetic acid bacteria are common microbes used in fermented mulberry foods. Nowadays, with considerable research work on medicinal and nutritious value of mulberry around the world, mulberry has been commercially processed into syrups, jam, fruit wine, distillates and liqueur and sometimes it is used for the extraction of colorants [4].

\section{Alcoholic Beverages Obtained from Mulberry}

Mulberry is a welcome ingredient in some alcoholic beverages with local characteristics around the world. Spanish inhabitants on the Canary Islands like to produce an alcoholic beverages using black mulberry through natural fermentation with the purpose of its natural therapeutic qualities for the control of type II diabetes mellitus [5] and inflammations of the throat, tongue and mouth [6]. Greeks traditionally made an alcoholic drink named "Mouro" coming from the distillation of fermented fruits of the mulberry [7]. Mulberry is also frequently used in a traditional Korean alcoholic beverage, yakju, to alter the flavors and taste of the final product. Dynamics of physicochemical properties and bioactivities such as antioxidantactivities of mulberry during fermentation is also conducted. In general, there is an increase in alcohol content and total acidity and a decrease in sugar level in comparison to the control. In contrast, the anthocyanin content decreased during the fermentation periods. The increase in antioxidant activities of mulberry yakju might have been affected primarily by the total flavonoid and total polyphenol content with increasing alcohol concentration, as a good extractor, during the fermentation [8]. Mulberry wine extract (MWE) could ameliorate metabolic disease through an improvement in mitochondrial functions such as increasing the expression levels of fatty acid oxidation related genes, transcription factor $A$ and the nuclear respiratory factor-1, mitochondrial oxidative complex proteins, and so on [9]. Volatile composition change during mulberry fermentation is specially concerned. The aromatic profile of mulberry wine was mainly characterized by phenylethyl alcohol, 1-decanol,3-ethoxy-1-propanol, ethyl acetate, isobutyl acetate, ethyl octanoate, isoamyl acetate, ethyl butanoate, ethyl hexanoate, and ethyl butyrate. Attributes such as fruity, solvent, floral and fatty had a significant increase in wines elaborated with skin contact $[10,11]$.

\section{Lactic acid beverages obtained from mulberry}

For a long time, lactic acid bacteria have played an essential role in the preservation of food raw materials and have contributed to the nutritional, organoleptic and health properties of human food products and animal feed. Lactic acid bacteria are involved in the formation of yoghurt, cheese, pickle, whey, soybean sauce, fermented-soybean and silage [12]. Generally speaking, lactic acid bacteria will format the lactic acid in the raw materials, which is capable of effectively protecting final fermented food products from beings abrogated by microorganisms. Besides, there are many other uses for lactic acid bacteria metabolism, for instance: enhancing the flavor and texture of products [13]. Several commercial strains like Lactobacillus acidophilus, Lactobacillus plantarum and Lactobacillus brevis and Leuconostoc mesenteroides are widely used individually or in combination.Mulberrywith large quantities of sugar is suitable for lactic fermentation and functional

*Corresponding author: Yu-Xiao Zou, Sericultural \& Agri-Food Research Institute, Guangdong Academy of Agricultural Sciences, NO.133 Yiheng ST, Dongguanzhuang RD, Tianhe District, Guangzhou 510610, PR China, Tel: +86-02 37227141; Fax: +86-02-87236354; E-mail: yuxiaozou@163.com

Received April 13, 2015; Accepted April 15, 2015; Published April 17, 2015

Citation: Zou YX, Shen WZ, Wang SY, Liao ST, Liu F (2015) The Roles of Fermentation Technologies in Mulberry Foods Processing: Application and Outlooks. Med chem 5: e107. doi:10.4172/2161-0444.1000e107

Copyright: ( 2015 Zou YX, et al. This is an open-access article distributed under the terms of the Creative Commons Attribution License, which permits unrestricted use, distribution, and reproduction in any medium, provided the original author and source are credited. 
compounds are expected to be increased after fermentation. X. Zheng et al. used probiotic Leuconostoc mesenteroides to ferment mulberry and found it is a good strategy to enhance its probiotic value and to decrease the sugar content without changing the anti-glucosidase activity, which is required to reduce postprandial rise in blood glucose [14]. An-Cheol Lee et al. reported a technique to develop new functional yogurts using mulberries, and a combine lactic strains including Lactobacillus acidophilus, Bifido bacterium bifidum, and Streptococcus thermophilus were used [15]. Turkey scientists researched a set-type yoghurts produced by addition of mulberry with high points of sensory evaluation and investigated its physicochemical, mineral and sensory properties [16].

\section{Vinegar beverage obtained from mulberry}

Vinegar is consumed worldwide as a food condiment andpreservative. In China, vinegar is traditionally produced by cerealwith a long history of more than 3000 years [17]. Since consuming vinegar on a regular basis can contribute to the maintenance of good health, many fruit vinegar products arereported and soldall over the world. Basically, fruit vinegar is made from juice mixed with grain vinegar, or from juice via alcoholic and vinegar fermentation. Mulberry vinegar was found to be higher in lactic and succinic acids than other fruit vinegar [18]. Mulberry vinegar is found effective in enhancing antioxidant defense in the diabetic state [19]. So far, commercial mulberry vinegar beverage products are much less than mulberry wine. It is an expected product by numerous abstainers.

In summary, fermented mulberry foods including wine, yoghurt and vinegar are important development direction. More and more mulberry foods based on fermentation technologies will be researched and produced to meet the healthy requirement of people.

\section{Acknowledgements}

We thank the Guangzhou external cooperation research project (NO. 2014J4500036), Special Fund for Agro-scientific Research in the Public Interest, China (No.201403064), the Key Projects in the National Science \& Technology Pillar Program during the Twelfth Five-year Plan Period, China (No.2013BAD16B09), and the Foundation of the President of the Guangdong Academy of Agricultural Sciences (No. 201433) for financial support.

\section{References}

1. Machii H, Koyama A, Yamanouchi H (2000) FAO Electronic Conference: Mulberry for animal production.

2. Ercisli S (2004) A short review of the fruit germplasm resources of Turkey. Genetic Resources and Crop Evaluation 51: 419-435.

3. Du Q, Zheng J, Xu Y (2008) Composition of anthocyanins in mulberry and their antioxidant activity. J Fd Compos Anal 21: 390-395.
4. Gerasopoulos D, Stavropoulos G (1997) Quality characteristics of four mulberry (Morussp) cultivars in the area of Chania. Greece Journal of the Science of Food and Agriculture 73: 261-264.

5. Ionescu-TÃ®rgoviÅŸte C, Popa E, Mirodon Z, Simionescu M, Mincu I (1989) The effect of a plant mixture on the metabolic equilibrium in patients with type-2 diabetes mellitus. Rev Med Interna Neurol Psihiatr Neurochir Dermatovenerol Med Interna 41: 185-192.

6. QuerP Font (1995)Plantasmedicinales. El Dioscóridesrenovado, Labor S.A 117-121.

7. Soufleros EH, Ageliki S, Mygdalia P, Natskoulis (2004) Characterization and safety evaluation of the traditional Greek fruit distillate "Mouro" by flavor compounds and mineral analysis. Food Chemistry 86: 625-636.

8. Kwak EJ, Lee JY, Choi IS (2012) Physicochemical properties and antioxidant activities of Korean traditional alcoholic beverage, yakju, enriched with mulberry. J Food Sci 77: C752-758.

9. You Y, Yuan X, Lee HJ, Huang W, Jin W, et al. (2015) Mulberry and mulberry wine extract increase the number of mitochondria during brown adipogenesis. Food Funct 6: 401-408.

10. Luchai B, Montri J, Sujitar J, Supachai S, Wannee S, et al. (2011) HS-SPMEGC-MS analysis of volatile aromatic compounds in alcohol related beverages made with mulberry fruits. Food Science and Biotechnology 20: 1021-1032.

11. Samappito S, Butkhup $L(2010)$ Effect of skin contact treatments on the aroma profile and chemical components of mulberry (Morusalba Linn.) wines. African Journal of Food Science 4: 52-61.

12. deVos WM, Hugenholtz J (2004) Engineering metabolic highways in Lactococci and other lactic acid bacteria. See comment in PubMed Commons below Trends Biotechnol 22: 72-79.

13. Kleerebezemab M, Hols P, Hugenholtz J (2000) Lactic acid bacteria as a cell factory: rerouting of carbon metabolism in Lacto coccuslactis by metabolic engineering. Enzyme MicrobTechnol 26: 840-848.

14. Zheng X, Yua Y, Xiao G, Xua Y, Wua J, et al. (2014) Changes of antiglucosidase content and some other characteristics in mulberry juice during fermentation with leuconostoc mesenteroides. Acta Alimentaria 43: 668-675.

15. An-Cheo Lee, Youn-Ho Hong (2010) Development of Functional Yogurts Prepared with Mulberries andMulberry Tree Leaves. Korean J Food Sci Ani Resour 30: 649-654.

16. Karaca OB, Saydam IB, Güven M (2011) Physicochemical, mineral and sensory properties of set-type yoghurts produced by addition of grape, mulberry and carob molasses (Pekmez) at different ratios. International Journal of Dairy Technology 65: 111-117.

17. Shi G (1999) Talk about Chinese vinegar. China Brewing 6: 39-40.

18. Chang RC, Lee HC, Andi S (2005) Investigation of the Physicochemical Properties of Concentrated Fruit Vinegar. Journal of Food and Drug Analysis13: 348-356.

19. Kim JY, Ok E, Kim YJ, Choi KS, Kwon O (2013) Oxidation of fatty acid may be enhanced by a combination of pomegranate fruit phytochemicals and acetic acid in HepG2 cells. Nutr Res Pract 7: 153-159. 